\title{
Clarification of the Training Requirements for Working on Electric Vehicles
}

\author{
http://dx.doi.org/10.3991/ijac.v9i1.5635 \\ H. Fechtner ${ }^{1}$, K.-H. Saes ${ }^{2}$, E. Fechtner ${ }^{1}$, T. Braun ${ }^{1}$, and B. Schmuelling ${ }^{1}$ \\ ${ }^{1}$ University of Wuppertal, Wuppertal, Germany \\ 2 TÜV NORD Bildung GmbH \& Co. KG, Essen, Germany
}

\begin{abstract}
The dwindling energy resources and the compliance of international climate protection goals lead to a rethink in the automobile sector. One result of this rethink is the increasing distribution of electric vehicles in the last years. This development includes a new challenge for the training sector. For example, the implementation of a highvoltage system into automobiles involves a new hazard potential for people, who work on electric vehicles. Therefore, the employees in the areas of vehicle repair trade, rescue services, towing services, and other relevant sectors need a good qualification for working on electric vehicles. On the one hand, a lot of specialized training programs have already been developed in the area of academic education. On the other hand, there is a great need of training programs for professionals (e.g. motor mechanics, firefighters). Hence, this paper clarifies the current requirements in the education sector and the new hazard potential by working on electric vehicles. Moreover, an approach for the development of a specialized training program for working on electric vehicles is presented in this paper as well. The focus of this training program is on the improvement of the learning process by a blended learning concept with an adaptive modular design.
\end{abstract}

Index Terms-adaptive modular design; electric vehicle; blended learning; new hazard potential;

\section{INTRODUCTION}

\section{A. General introduction}

There are many reasons for using an electric vehicle (EV). Two of the most important points are the dwindling oil reserves and the global warming. The pros of driving an EV outweigh the cons. For example, the operation costs of an EV are significantly lower than the operating costs of a vehicle with a conventional internal combustion engine (ICE). But in practice, the picture is completely different. In particular, the major barriers for buying an $\mathrm{EV}$ are the high purchase price, the insufficient charging infrastructure, and the limited range. Nevertheless, 550,000 new EVs have been registered in 2015 worldwide. This development means that in total 1.3 million EVs have been on the worldwide streets on 1 January 2016 [1]. The actual sales volumes of EVs worldwide are in comparison to the sales volume of vehicles with an ICE very low. However, the employees who have contact to EVs in their everyday working life need a specialized training program for working on EVs.

For example, if the owners of an EV have some problems with their EV (e.g. error message in the display) they bring their car to an authorized workshop. In this case, the motor mechanics must be well qualified for working on EVs. The employees of authorized workshop are mainly trained by training offers of the several automobile manufactures. Hence, beside the authorized workshops independent car workshops with good trained employees in the area of E-Mobility will be needed too. This is very important to stimulate the competition inside the service sector and to reduce the repair costs for the owners of EVs.

\section{B. Project goal}

In comparison to other current training programs (see chapter 2) the project team will develop an adaptive education program for several occupational groups (OG) (motor mechanics, rescue teams, vocational school teacher etc.). For this reason, the program will have an adaptive structure with a very detailed modular design, see Figure 1. Another specific feature of this project is the issue of a personal certificate after a successful graduation of the training program. With regard to the technical theme "EMobility" the project team decided that the didactic method "blended learning" is the best solution for this. The reasons for this decision and whether blended learning is really the best solution for this project will be further explained in the following sections. However, at first some related works will be presented to give a first overview of the actual situation in the educational sector relating to E-Mobility.

\section{RELATED WORK}

\section{A. Education in the context of E-Mobility worldwide}

A lot of training programs in the context of E-Mobility were presented in the past. The most of the programs are in academic context (e.g. for students). For instance, the authors of [2] present a new interdisciplinary program for graduate and undergraduate students in advanced electric

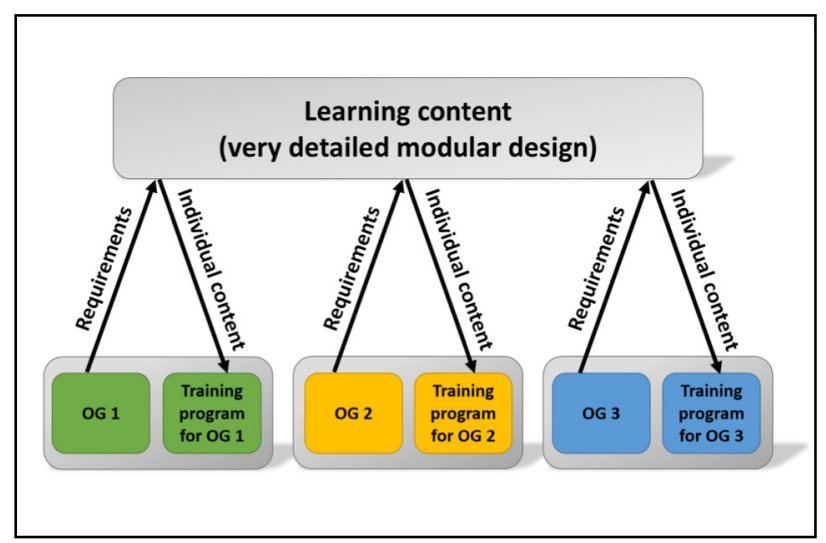

Figure 1. Basic idea of the training program (simplified representation). 
drive vehicle engineering. The course contains some practical exercises, like measurements at an EV in the lab. Furthermore, a distance learning program is another component of the course, which is developed by the Michigan Technological University.

Another program for students is illustrated in [3]. The Kettering University designed in cooperation with some companies from Michigan a hybrid electric vehicle education program, which based on corporate needs. One interesting aspect is that the companies give an input for the development of the curriculum. This allows for establishing a program with a practical orientation. The target group of this program are students, so this course is similar to [2]. This is only a small excurse to the academic education and do not represent all programs worldwide (like [4], [5], [6]).

For reaching the project goal it is indispensable to analyze projects with regard to training programs for professionals. For example, the author of [7] presented a concept for an advanced electric vehicle education program. The National Alternative Training Consortium (NAFTC) is responsible for reaching this project goal. The NAFTC aims to develop a training program for first responder, automotive technician, and some further occupations and they want to deliver the courses to over 20,000 individuals.

As already mentioned, emergency responders (firefighters, rescue teams etc.) are another relevant occupational group who need a very detailed training program for the topic E-Mobility. For example, the National Fire Protection Association (NFPA) offers a specialized training program for emergency responders [8]. This course comprises animations, simulations and some further contain in the context of different alternative fuel vehicles. The training program is a pure online course. The goal of this project is to prepare the emergency responders for working on alternative vehicles. For reaching this goal the NFPA works together with General Motors and Chevrolet.

In short summary: Currently, there is a great offer of training programs for working on EVs in the range of academic education (undergraduate, graduate or $\mathrm{PhD}$ students). But the majority of the presented projects is not for professionals, who have a long experience in their job, like motor mechanics. Nevertheless, for a good educated automotive service sector (e.g. workshops) a specialized training program is required. Another important distinctive point in comparison to existing training programs is that the project team will develop an adaptive training program. This makes the training of different occupational groups with only one training program possible.

The following analysis was on training programs for professionals in the area of E-Mobility, which are actually offered. The further education program shown in this paper is for the German training sector. Therefore, programs in Germany are mainly analyzed. However, it is transferable to other countries worldwide as well.

\section{B. Education in the context of E-Mobility in Germany}

In [9], the German government and especially the National Platform for Electric Mobility (NPE) are clarifying the needs of education and training for EVs. They are underlining the result from the literature research above. In the field of academic education a large number of content for the topic "E-Mobility" have already developed. In comparison to this, the authors of [9] mention that there is an urgent backlog of training programs for postgraduates, apprentice, and professionals.

As part of the investigation 24 research projects, 15 software/tools and 15 current training programs have been identified and analyzed (especially [10], [11]). The analysis should help to answer the following question: What are the target groups of current training offers for working on EVs in Germany? It should be noted that the presented results reflect the status of August 2015 and only displayed freely selected projects and not all present projects in Germany. Nevertheless, the results give a good insight of the status quo in Germany.

In relation to the interpretation of the research results, it should be noted that it is possible that the analyzed projects, training programs, and software/tools are for two or more target groups at the same time (multiple answer possible). The result of the analysis of 24 current research projects in the range of E-Mobility clarifies that 13 of these projects are developing training programs for professionals, six for apprentices, and six for students. A similar result entails the analysis of current training programs. 13 of the 15 analyzed training programs are for apprentice, 12 for professionals, and eight for pupils.

Another emphasis of the analysis was the identification of the target groups of current software/tools for the topic E-Mobility. The most software/tools are developed for professionals $(n=15)$. Only two of the 15 analyzed software/tools are for further target groups (e.g. interested citizens).

As a complement to the own results, another research project will be presented. The project "NquE Networking for Electric Mobility Education and Training" aims among other goals to identify the best practice results from education initiatives in Germany. This research including vocational and academic education as well as continuing professional development [9]. As of February 2016, "NquE" has identified 16 programs for vocational education (e.g. professionals or apprentice) and 32 programs for academic education students (six bachelor and 26 master programs). It must be pointed out that nine of 32 academic programs are for extra-occupational education [12], [13].

The result of the analysis of some free selected research projects, training programs, and software/tools emphasizes again the research needs in the field of continuing education, because the main focus of the research projects are on training programs for professionals. In addition, the results of "NquE" show that in comparison to training programs for vocational education $(n=16)$ a lot of programs for the academic sector $(\mathrm{n}=32)$ already exist.

\section{Blended learning}

As described above, the plan of the project team is to develop a blended learning training program for working on EVs. In view of this decision, some publications relating to blended learning have been analyzed.

In the literature different definitions of the term blended learning occur, i.e. there is no uniform definition [14]. In [15], Picciano illustrates some different definitions of blended learning. For example, on the one hand blended learning can be a mix of online learning and 
face-to-face instruction. On the other hand it can be a mixture of traditional lecture and some electronic instructor notes and handouts (e.g. with graphs or charts) [15]. In comparison to this definition, the authors of [16] and [17] describe blended learning as a didactical method which is using more than one delivery mode. This is a very simple but nevertheless apt description. Anyhow, according to [14], [15], and [18], the most common definition of blended learning is a combination of face-toface instruction and online content.

Hence, this didactical method combines the strength of both and reduces some weaknesses. A particularly negative example of a pure e-learning program is the reducing of the social contact in comparison to a pure face-to-face program [19], [20]. A further disadvantage of e-learning is that the participants need a greater discipline for processing the content of the online course [21]. To point out the advantages of blended learning, some important examples are shown in the following.

Blended learning enabled more opportunities for providing learning resources [22]. The availability of requested material with easy access and the possibility of repeating the content any time ("24/7") is another advantage [19], [22], [23]. Furthermore, the option to contact the teacher directly and personally (eye-to-eye) in comparison to a pure e-learning program provides the opportunity that the participants can socialize face-to-face with the other participants of the blended learning program [23], [24]. Moreover, blended learning gives the possibility of improving the motivation of the participants and to promote the self-study of the participants [25], [26].

Additionally, the NMC Horizon Report 2015 [27] also emphasizes that blended learning could stimulates the social exchange between the participants and the critical thinking of them. Furthermore, the report concludes that there is an increasing demand for easy accessible learning content [27].

The advantages of blended learning outweigh the disadvantages of a pure e-learning or a face-to-face instruction program. Another important aspect for using blended learning is that the training program must have a practical orientation (e.g. practical exercises on an EV). In particular, the possibility of repeating the content any time is a key benefit for a professional, who works during the day (keyword: extra occupational education).

\section{WORKING ON ELECTRIC VEHICLES}

\section{A. EVs: actual situation in Germany and worldwide}

For a better understanding of the actual situation in Germany and for the presentation of occupational groups, which may be in contact with EVs, some facts will be shown in the following.

In the context of the German "Energiewende" ("energy transition") the distribution of EVs is among other technology innovations (e.g. smart grids, renewable energies) very important for the reduction of $\mathrm{CO}_{2}$ emissions. For example, one main objective of the German government is to reach one million EVs on the German streets in 2020 [28]. In the year 2015, only 33,630 new hybrid electric vehicles (HEV) and 12,363 new EVs were registered in Germany [29]. For this reason, the German government is still far from achieving this goal. In contrast to Germany, 247,482 EVs have sold in China in 2015 [30]. In view of the future political goals for the

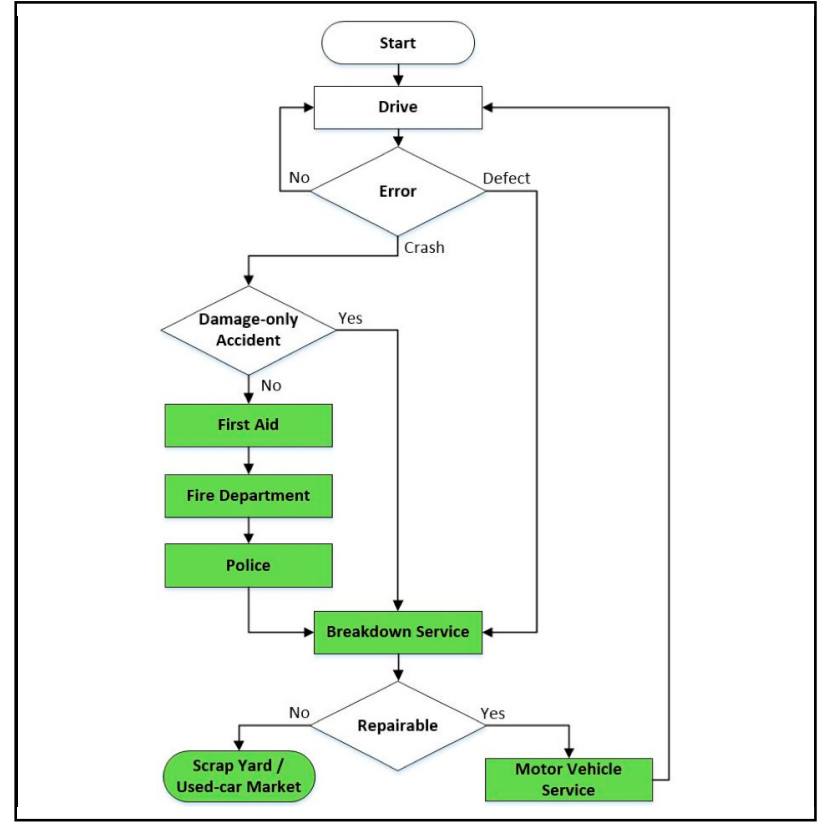

Figure 2. Sample scenario: potential target groups (marked green)

year 2020 of China (11.9 million EVs), USA (3 million EVs), and Germany (1 million EVs) [31], the topic EMobility will become more and more important inside the training sector.

Besides reducing the purchase price of EVs or the increasing of the range of EVs, another important aspect to raise the willingness to buy an EV, is the training of people who work on EVs. This is based on the assumption that every car owner wants his EV in good and especially in competent hands. Hence, the next sections of this paper presented some relevant occupational groups and the necessity of training programs for employees, who work on EVs.

\section{B. Relevant occupationals: actual situation in Germany}

In 2014, 462,000 people are employed in 38,500 car workshops in Germany [32]. 17,500 of the workshops are manufacture authorized workshops and 21,000 are independent ones [33]. Approximately 270,000 of the employees are working in a technical occupation and 72,400 are apprentices with a technical background [32].

Since June 2013, the topic "E-Mobility" is part of the training plan for the education of automotive mechanics in Germany [34]. Thus, the focus of this paper is on the development of a further education program for motor mechanics, who started their vocational training before June 2013 (e.g. professionals or apprentices).

The sample scenario in Fig. 2 illustrates some potential occupational groups along the value chain of an EV. This figure clarifies that there are some more occupations beside the motor vehicle service area. For example, rescue teams, first responders, firefighters, police officers, and employees of wrecking, breakdown or towing services are also relevant occupations (marked green in Fig. 2). Furthermore, teachers at vocational schools are another very important target group, as they have the task to disseminate the knowledge about working on EVs (keyword: multiplier).

Beside the motor mechanics, firefighters are also a very important occupational group relating to the topic EMobility. In 2013, the several German fire departments 
have in total over 1.3 million members [35]. In the context of the increasing distribution of EVs the numbers of traffic accidents with EVs will also increase. Therefore, the large number of the potential occupations, in particular motor mechanics and firefighters, is one of the reasons for the adaptive structure of the training program presented in this paper (see chapter 7).

\section{Necessity of a training program for working on $E V S$}

The rise of the sales number of EVs is associated with an increasing of necessity of a specialized training program for working on EVs in the future. Some of the reasons of the new challenge for the training sector will be shown in this section.

The most important distinctive point of EVs in comparison to conventional cars is the implementation of a high voltage battery into the cars. The definition of highvoltage according to the European ECE R100 [36] and the American SAE J1766-2014 [37] is for AC between $30 \mathrm{~V}$ and $1000 \mathrm{~V}$ and for DC between $60 \mathrm{~V}$ and $1500 \mathrm{~V}$.

The voltage of a typical battery for EVs is $355 \mathrm{~V}$ DC [38], but for example, the voltage level could be higher than $355 \mathrm{~V} \mathrm{DC}$, like the high voltage battery of the most sold EV worldwide Nissan Leaf [39] with $360 \mathrm{~V}$ DC [40]. According to [41], the automobile manufactures planned batteries with voltages up to $850 \mathrm{~V}$ DC for commercial EVs in the future. Thus, the utilization of high voltages in the automotive sector has a new hazard potential, like getting an electric shock or burn injuries.

EVs provide some internal safety measures to protect people against getting an electric shock, like the service disconnect. By using this measure the high voltage loop shuts down. Nonetheless, for employees in the area of vehicle repair trade the participation at specialized training programs is defined by law (e.g. [34], [42]). For example, they need to know the position of the several protective mechanisms in the car and how they work.

A detailed description of some potential hazards and a detailed listing of components and their risk potential will be presented in next chapter.

\section{Health risk}

The implementation of several electrical components and a high-voltage system into the automobiles entails that by working on EVs some special protective measures are needed. In order to clarify this situation, some selected components of EVs and their health risk will be presented.

The health risk for people who work with EVs is not negligible. For example, a motor mechanic, who touches a high-voltage cable or an energy storage with an insulation fault, could get an electrical shock. In the consequent of the electrical shock, there is the possibility of getting a

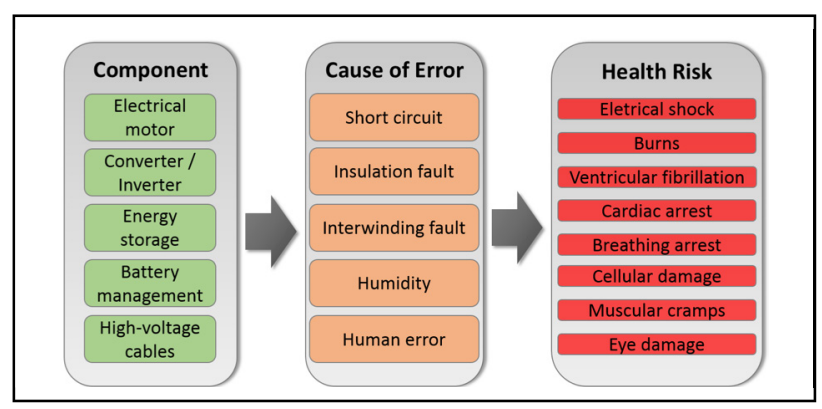

Figure 3. Health risk of some selected components

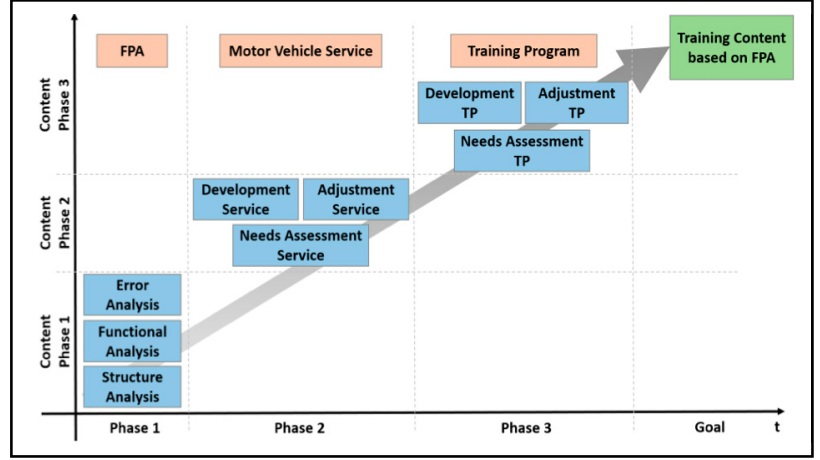

Figure 4. Fault probability analysis ("3-phase model”)

ventricular fibrillation or burns (see Fig. 3).

Hence, it is very important that the people who work on EVs are highly qualified. This includes inter alia the knowledge about: location of the components, potential health risk of high-voltages as well as high currents, correct handling with the personal protective equipment, first aid measures, and adherence to safety rules (e.g. switching off the high-voltage system).

\section{FAULT PROBABILITY ANALYSIS}

\section{A. Goal}

The goal of the fault probability analysis (FPA) is the identification of the training needs for working on EVs and of some new services for the automobile sector. Therefore, a number of different methodologically approaches are used (see Fig. 4). The results of the FPA are inter alia the basis for the development of new training contents.

\section{B. Methodology}

The proposed approach contains three different phases, which are described in the following sections.

Phase 1: The structure analysis is the first part of this phase. The aim of this analysis is the identification of the components of an EV and especially the potential risk of them (e.g. burns, electrical shocks). The next step is the functional analysis. The goal of this step is to design a functional correlation between the several components and subsystems of an EV. The third task of phase 1 is to identify potential errors in the everyday use of an EV. Therefore, the project team developed a logbook. This logbook has been dispatched to 30 drivers of an EV. The logbook will be collected every sixth months. It is planned to dispatch this book to further drivers during the project duration of 36 months. To identify the potential errors, the drivers have the possibility to notice inter alia the following errors: errors before, during, and after driving (e.g. unusual noises or handling); problems with the onboard electronics (e.g. incorrect display); problems or error at the charging process (e.g. involuntary interruption). The drivers could write down the cause of the error, how the error has been identified, and how the error has been fixed. From this result, some new contents for the training program respectively some new services for the automobile sector could be identified.

Phase 2: The second phase includes the needs assessment of new services for EVs in the range of motor vehicle services. For this goal the project team analyzed the results of phase 1. In particular, the new findings of the error analysis will be very informative in relation to 
the identification of the necessity. Based on the needs assessment and further analysis some new services will be developed or rather existing services will be adjust.

Phase 3: The last step is the development of new training programs (TP) respectively the adjustment of existing training programs. This approach based on the results of phase 2 . The development of some new services entails that some new specialized learning contents must be designed. The goal of developing a new training program based on the FPA will be achieved after phase 3 . The FPA is an iterative approach and will take the whole project duration of 36 month.

\section{First results}

The first results of the evaluation of the logbooks shows that the owners of EVs have mainly the same problems like owners of conventional cars (e. g. problems with the brake system). One important result is that almost all of the owners of EVs bring their car to a manufacture authorized workshop. The possible motives for this user behavior will be shown in the next section.

\section{PRESENTATION OF THE SURVEY RESUltS}

\section{A. Goal}

As shown in the previous chapter, the identification of the needs of qualification measures for working on EVs is an important element for reaching the project goal. Beside the FPA the project team has performed one survey at a chamber of crafts and at one location of a training organization in Germany. The second survey was an online survey and was issued to relevant occupational groups. The surveys were designed to help the project team to determine inter alia the willingness of future master craftsmen (motor mechanics with professional experience) and other occupational groups to participate in a specialized training program and how they assess the health risk for working on EVs. All participants of the surveys have practical experience in working on vehicles.

\section{$B$. Results of the surveys}

In total, the first survey included 26 questions to different topics of E-Mobility. The survey was issued to 160 future master craftsmen in the area of motor vehicle service. $40 \%(n=63)$ of the potential participants have filled out the survey.

$77.78 \%$ of the pupils have the opinion that working on EVs has new hazard potential for car mechanics and only $6.35 \%$ think that there is no difference to conventional cars. Moreover, $52.38 \%$ think that the current training programs are insufficient relating to work on EVs and only $1.59 \%$ have the opinion that there is already a sufficient number of well qualified professionals for working on EVs.

One alarmingly result of the survey is that one third of the interviewees have already worked on EVs without the required qualification. Some of the pupils $(n=5)$ have worked more than 10 times on an EV. In context of the potential health risk of high-voltage system, the results of the survey underline, how urgent a specialized training is.

A further questions clarifies that $46.03 \%$ of the pupils think that working on EVs is more complicated in comparison to working on conventional vehicles. $57.14 \%$ of the participants have the opinion that the integration of

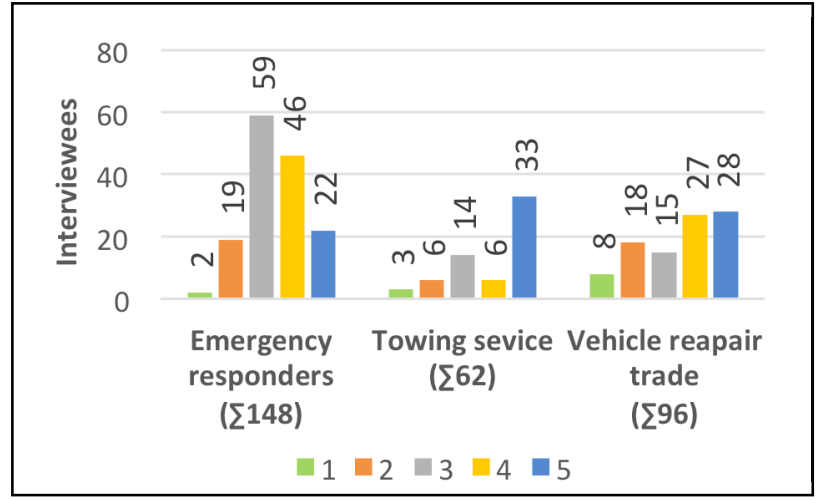

Figure 5. Risk by working on EVs (1=low; 5=high)

content with regard to EVs into the training programs for motor mechanics is very useful.

The following results of the survey are very meaningful for the development of the didactic methods, the modular design, and the learning content. The most important contents are working on EVs $(63.49 \%)$, energy storages $(60.32 \%)$, drive technology $(57.14 \%)$, and charging technology (57.14\%). Moreover, $30.16 \%$ think that an elearning system is very helpful, but $55.56 \%$ are of the opinion that a face-to-face teaching is the best didactic method. Furthermore, $63.49 \%$ of the interviewed persons think that simulations and animations are the most important features for the e-learning system and 50.79\% of the pupils will support the development of an app (mlearning). In addition, $49.21 \%$ of them will use the app for the exam preparation. Furthermore, approximately one third $(34.92 \%)$ of the pupils are describing that the high costs for a training program for working on EVs are the main reason for a non-participation in existing courses.

The second survey was an online survey. This survey issued to the three relevant groups: emergency responders $(n=148)$, employees of breakdown and towing service $(n=62)$, and employees in the area of vehicle repair trade $(n=96)$. Thus, in total 306 interviewees have filled out the survey. Only the most important results will be shown in the following.

$53 \%$ of the interviewees $(n=162)$ think that working on EVs has a high hazard potential, see Fig. 5 (response option 4 and 5). In comparison to this, only $20 \%(n=61)$ of the interviewed persons have the opinion that working on conventional cars have a high risk. Therefore, the second survey confirmed the results of the first survey.

Another important point relating to the development of the training program are the new requirements for working on EVs. Approximately $70 \%$ of the participants

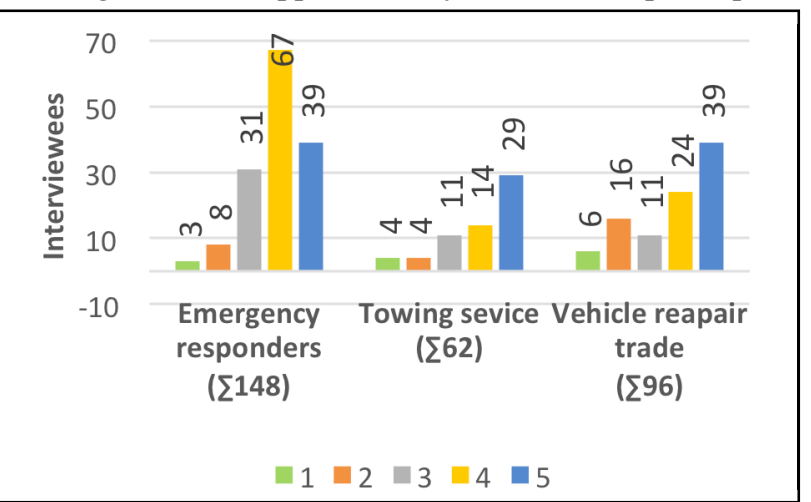

Figure 6. Requirements for working on EVs (1=low; 5=high) 
$(n=212)$ think that the requirements are high, see Fig. 6 (response option 4 and 5). In comparison to the result of the same question but in this case relating to conventional cars nearly the half of the interviewees $(n=152)$ have the opinion that the requirements for working on conventional cars are high.

The next results show the different qualification needs of manufacture authorized workshops and independent ones. $82 \%$ of the manufacture authorized workshops have employees, who are qualified for working on EVs. In comparison to this, only $44 \%$ of the independent workshops have employees with the necessary qualification.

\section{Results discussion}

The results of the surveys underline that the implementation of a high-voltage system into automobiles causes a higher risk for working on EVs. Furthermore, the results confirm the adoption that blended learning will be the best choice for a training program for working on EVs. With this approach, it is possible to integrate different learning styles and to reduce the disadvantages respectively to reinforce the advantages of the different didactic methods. In relation to the results, the implementation of an e-learning system provides the opportunity of reducing the course costs [20]. Furthermore, the survey results illustrate the greater requirements based on the new technology, especially the high-voltage system. That there is a new hazard potential by working on EVs is a further result of the survey. For this reason and in the context of the future increasing distribution of EVs the development of a specialized training program for working on EVs is very important, in particular against the background of the new potential health risk caused by the high-voltage system. In addition, the survey results clarify the qualification needs of employees of independent workshops.

\section{PRESENTATION OF THE DIDACTIC CONCEPT}

As described before, the project team developed a blended learning training program for working on EVs, see Fig. 7. In the following the individual methods of the didactic concept will be explained in detail.

For the training program lecture and face-to-face instruction were chosen from the classical didactics. The lecture is to impart all participants with the same level of knowledge shortly in an efficient way, but it should be combined with other methods like face-to-face instructions, where the learners are not just in a passive way and can process as much information. Face-to-face instruction compensates this disadvantage by the

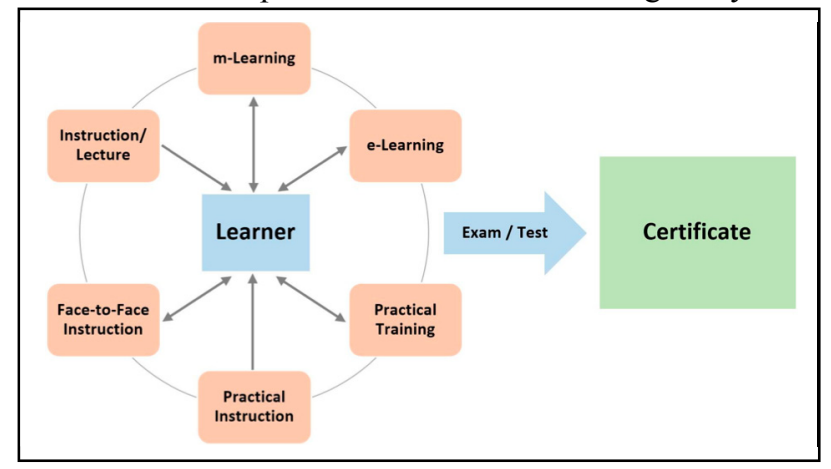

Figure 7: Didactic concept for the training program

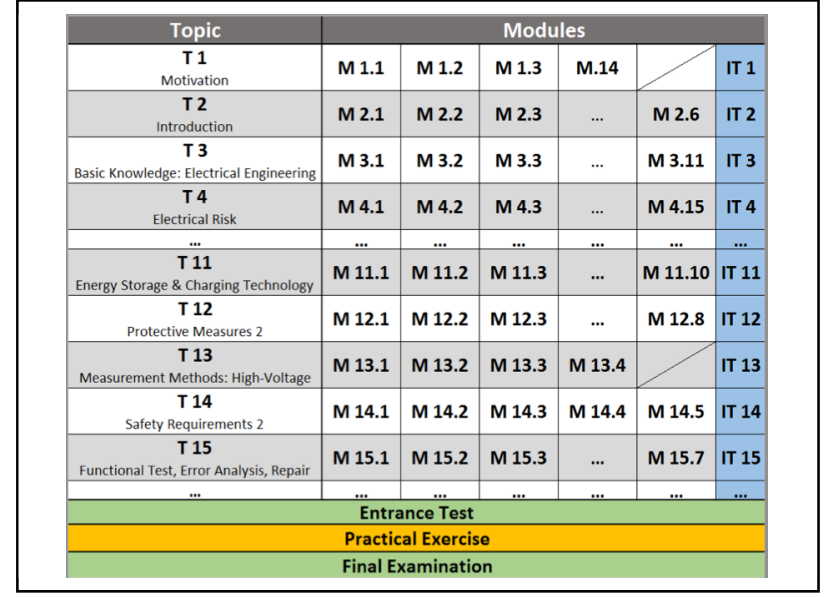

Figure 8. Modular design of the training program

mediation of theoretical knowledge with active participation of the pupils.

Another important parts of the training program will be the practical modules. The practical instruction and training are used to put previously mediated theoretical knowledge into practice. Through the practical action, the acquired knowledge will be consolidated.

To complement the blended learning concept two more didactical methods are chosen. One is e-Learning, which means all learning content is permanently available online. This makes the learning process more flexible then the other above described methods, because the pupils are independent of in-class lectures and can make an individual time management for self-contained learning.

The other method is $\mathrm{m}$-Learning. It is an extension of the e-learning model due to the fact that all learning content is permanently available online by an app. So the pupils are no longer dependent on stationary internet access points, but rather have access to the learning content with their portable devices anytime and anywhere. This increases the flexibility by far. The mobile learning app can also provide a wiki or a forum for the participants, where they can find prescribed definitions about the learning content (e.g. emergency response guides for different EVs) and have furthermore the opportunity to describe their own experience of working on EVs and discuss them with the other course members.

The used blended learning concept is a mix of methods which interact with the learner on the one hand or just give a one-way input on the other hand. If the pupils are sufficiently prepared by the different parts of the training program, they can pass an exam and receive a personal certificate (see Fig. 7).

\section{STATUS QUO OF THE TRAINING PROGRAM}

Based on the results of the research, the statutory specifications, and the results of the survey, the project team developed a training program for motor mechanics. It should be emphasized that the presented modular design is a preliminary version. Especially the results of the fault probability analysis will be implemented continuous in the future modular design (keyword: iterative approach). The modular design contains 17 topics (see Fig. 8). Every topic is divided into a several number of modules. The processing time for solving all modules will take in total 32 hours. Additionally to this theoretical contents, the 
training program includes some practical exercises. The practical part will take 8 hours. Therefore, the complete training program for working on EVs will take 40 hours without the final examination at the end of the course. In order to get a quick overview of the modular design, some examples of the individual 17 topics are listed in the following.

Topic 1 "Motivation" (T 1): The goal of this topic is to motivate the pupils for the subject "E-Mobility". The motivation is a very important factor for a successful training program. This assumption based inter alia on the result of the survey. The result shows that only $39.7 \%$ of the surveyed persons have already engaged with the topic "E-Mobility". Therefore, the pupils need compelling examples and arguments to illustrate the needs for a training program for working on EVs. For reaching this goal, the following modules will be used: general insight into E-Mobility (M 1.1), historical review (M 1.2), necessity for the qualification (M 1.3) etc.

Topic 4 "Electrical Risk" ( $\mathrm{T}$ 4): The implementation of voltages over $60 \mathrm{~V}$ DC into the automotive sector involves that the topic "Electrical Risk" is essential for a training program for working on EVs. The main objective is to demonstrate the risks associated with working on EVs, particular the health risk (e.g. burns, electric shock). The modules of this topic are for example: effects on humans (M 4.1), threshold (M 4.2), first aid (M 4.14) etc. This topic is good example for the design of an adaptive structure. The modules of this topic are also relevant for the other potential occupational groups. The same applies to the next topic.

Topic 14 "Safety Requirements 2" (T 14): In context of the high-voltage system of EVs, the safety requirements must be presented in the training program. The goal of this topic is to demonstrate the risks by working on EVs and how the employee can be protected. T 14 consists of the hereinafter modules: security technologies (M 14.1), personal protective equipment (M 14.2), risk assessment (M 14.3) etc.

The aim of this very detailed modular design is the adaptability of the training program for many different target groups. Fig. 9 illustrates the adaptive approach of the training program. Depending on the several occupational requirements, the learning management system (LMS) will choose the necessary modules.

After every topic, respectively after finishing all modules of each topic, the pupils must pass an intermediate test (IT), see Fig. 8. The test includes different tasks about the content of the topic. Beside

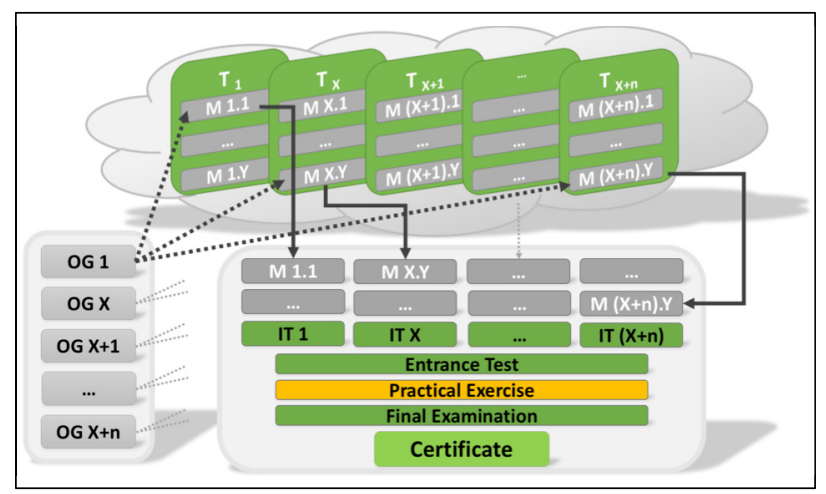

Figure 9. Example of the adaptive structure

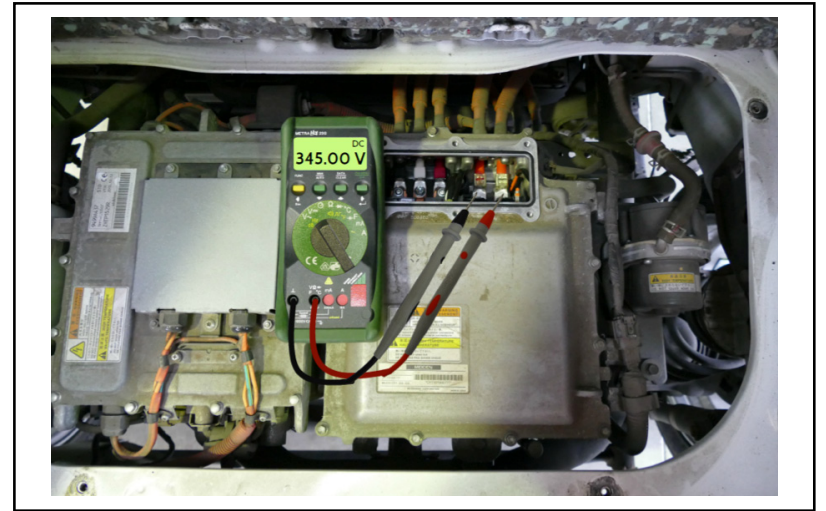

Figure 10: Interactive measurement at the inverter of an EV

multiple choice questions the pupils must solve some interactive exercises (e.g. measurements at an inverter of an EV), as you can see in Fig. 10. The tests are a preparation for the entrance test. The entrance test muss passed with at least $50 \%$ correct answers. Otherwise, the pupils are not authorized for the practical exercise and especially for the final examination. This part of the training program consists of a practical instruction by the trainer and some practical training by the pupils. For example, the trainer demonstrates how the high-voltage system of an EV can be disconnected. This demonstration will be performed under real conditions on an EV. Subsequent to the practical instruction, the pupils must pass some practical exercises at a demonstrator. The demonstrator is operating with harmlessly voltages and currents so that there is no health risk for the pupils.

\section{CONCLUSION}

This paper presents a new approach for developing a training program for working on EVs. Based on the result that there is a great need of specialized training programs for further education, the target groups of this program are professionals, like motor mechanics, firefighters or vocational school teachers. For reaching this goal, the paper clarifies the different health risks (e.g. electrical shock, burns), which arise by working on EVs. Furthermore, the paper shows an iterative concept for a fault probability analysis (FPA) to identify potential errors in the everyday use of EVs. In addition to the FPA, two surveys were performed. One important finding of the first survey is that one third of the interviewees have already worked on EVs without a required personal certificate. Therefore, the results underline, how urgent a specialized training is.

Hence, the project team developed a didactic concept, which integrates the results of the analysis of the state of the art and the results of the FPA as well as of the surveys. The project team has made the decision that a blended learning method is the best choice for a further education program for working on EVs. Especially the use of blended learning respectively of e-learning is a key benefit for a professional, who works during the day (keyword: extra occupational education). Moreover, the paper shows the adaptive structure of the training program respectively of the e-learning platform. The centerpiece of this concept is the very detailed modular design. This approach makes the realization of individualized training programs for different occupational groups possible. 
Finally, the status quo of the developed modular design is shown in this paper with the information that the modular structure depends on an iterative process. Therefore, the modular design will change in the future. The further development of the project, like the development and evaluation of the prototype of the elearning platform, the further results of the FPA, and the enhancements of the modular design, will be presented in following publications.

\section{ACKNOWLEDGMENT}

The authors acknowledge the funding of the research project EmoTal by the German Federal Ministry of Education and Research ("Bundesministerium für Bildung und Forschung").

\section{REFERENCES}

[1] Research Center for Solar Energy and Hydrogen , " Number of electric cars worldwide climbs to 1.3 million," February 5, 2016. [Online]. Available: http://www.zsw-bw.de/en/support/pressreleases/press-detail/number-of-electric-cars-worldwide-climbsto-13-million.html. [Accessed: March 8, 2016].

[2] W. Weaver, C. Anderson, J. Naber and J. Keith, "An Interdisciplinary Program for Education and Outreach in Hybrid \& Electric Drive Vehicle Engineering at Michigan Technological University," in IEEE Vehicle Power and Propulsion Conference (VPPC) 2011, Chicago, USA, 2011. http://dx.doi.org/10.1109/ vppc.2011.6043140

[3] J. Gover, M. Thompson and C. Hoff, "Design of a Hybrid Electric Vehicle Education Program Based on Coprorate Needs," in IEEE Vehicle Power and Propulsion Conference (VPPC) 2010, Lille, France, 2010.

[4] G. N. Reddy, "An EV-Simulator for Electric Vehicle Education," in IEEE International Conference on Engineering Education (ICEED 2009), Kuala Lumpur, Malaysia, 2009. http://dx.doi.org/10.1109/ICEED.2009.5490597

[5] A. Rojko, M. Spaner and D. Hercog, "Sustainable energy education: hybrid electric vehicles," in IEEE 11th International Conference on Remote Engineering and Virtual Instrumentation (REV), Porto, Portugal, 2014. http://dx.doi.org/10.1109/ rev.2014.6784183

[6] U. Schäfer, "Electric Vehicles - Educational Aspects," in IEEE XXth International Conference on Electrical Machines (ICEM 2012), Marseille, France, 2012. http://dx.doi.org/10.1109/ ICElMach.2012.6350322

[7] A. Ebron, "Advanced Electric Drive Vehicle Education Program Overview," World Electric Vehicle Journal, vol. 5, pp. 970-974, 2012.

[8] National Fire Protection Association, "Alternative Fuel Vehicles Safety Training Program," [Online]. Available: http://www.evsafetytraining.org/. [Accessed: February 22, 2016].

[9] German National Platform for Electric Mobility, "Progress Report 2014 - Review of Pre-Market Phase," Federal Ministry of Transport and Digital Infrastructure, Berlin, Germany, 2014.

[10] German Government - Showcase Program, "Project Profiles," [Online]. Available: http://schaufenster-elektromobilitaet.org/en/ content/projekte im ueberblick/projektsteckbriefe/projekte.html. [Accessed: August 10, 2015].

[11] Bayern - Sachsen: Elektromobilität verbindet, "Projekte," [Online]. Available: http://www.elektromobilitaet-verbindet.de/ projekte.html. [Accessed: August 10, 2015].

[12] NquE - Networking for Electric Mobility Education and Training, "Qualifizierungsangebote im Bereich Berufsbildung," [Online]. Available: http://www.nque.de/de/datenbank beruflich.php. [Accessed: February 23, 2016].

[13] NquE - Networking for Electric Mobility Education and Training, "Qualifizierungsangebote im Bereich akademische Bildung," [Online]. Available: http://www.nque.de/de/datenbank akademi sch.php. [Accessed: February 23, 2016].
[14] M. Tayebinik and M. Puteh, "Blended Learning or E-learning?," IMCAST, pp. 103-110, February 1, 2015.

[15] A. G. Picciano, "Blended Learning: Impacts for Growth and Access," Journal of asynchronous learning networks, pp. 95-102, January 2006.

[16] J. Pankin, J. Roberts and M. Savio, "Blended Learning at MIT," 2012.

[17] H. Singh and C. Reed, "A White Paper: Achieving Success with Blended Learning," Centra Software, 2001.

[18] A. G. Picciano, Blended Learning, New York, USA: Routledge , 2014.

[19] B. Akkoyunlu and M. Y. Soylu, "A Study of Student's Perceptions in a Blended Learning Environment Based on Different Learning Styles," Educational Technology \& Society, pp. 183-193, 2008.

[20] E. T. Welsh, C. R. Wanberg, K. G. Brown and M. J. Simmering, "E-learning: emerging uses, empirical results and future directions," International Journal of Training and Development, vol. 7 , no. 4 , pp. $245-258,2003$. http://dx.doi.org/10.1046/j.13603736.2003.00184.x

[21] F. Z. Azizan, "Blended Learning in Higher Education Institution in Malaysia," in Regional Conference on Knowledge Integration in ICT 2010, Putrajaya, Malaysia, 2010.

[22] X. Shen, D. Gao, Y. Ning and L. Pei, "Study on Blended Learning Supported by Network Curriculum," in IEEE International Conference of Educational Innovation through Technology (EITT) 2014, Brisbane, Australia, 2014. http://dx.doi.org/10.1109/eitt. 2014.26

[23] T. Horvat, T. Alajbeg and S. Predanic, "Experiences and Practices in Blended Learning Environment," in IEEE 38th International Convention on Information and Communication Technology, Electronics and Microelectronics (MIPRO) 2015 , Opatija, Croatia, 2015. http://dx.doi.org/10.1109/mipro.2015.7160409

[24] A. Heinze and C. Procter, "Reflections on the use of blended learning," University of Salford, Salford, UK, 2004.

[25] N. Buzadjija and D. Tiro, "Influence of Exercises on the Final Result in the Blended Learning Environment," in IEEE Fourth International Conference on e-Learning 2013, Manama, Bahrain, 2013. http://dx.doi.org/10.1109/econf.2013.23

[26] L. Zhang and X. Zhao, "The Design of Blended Learning Based on the Education Platform," in IEEE Chinese Automation Congress (CAC) 2013, Changsha, China, 2013. http://dx.doi.org/10.1109/cac.2013.6775862

[27] L. Johnson, S. Adams Becker, V. Estrada and A. Freeman, " NMC Horizon Report: 2015 Higher Education Edition.," The New Media Consortium, Austin, USA, 2015.

[28] B. Propfe, D. Kreyenberg, J. Wind and S. Schmid, "Market penetration analysis of electric vehicles in the German passenger car market towards 2030," International Journal of Hydrogen Energy, pp. 5201-5208, May 1, 2013.

[29] Kraftfahrt-Bundesamt, "Pressemitteilung Nr. 01/2016 Fahrzeugzulassungen im Dezember 2015 - Jahresbilanz," January 6, 2016. [Online]. Available: http://www.kba.de/DE/ Presse/Pressemitteilungen/2016/Fahrzeugzulassungen/pm01 2016 n_12_15_pm_komplett.html? $\mathrm{nn}=716864$. [Accessed: February $25,2016]$.

[30] China Association of Automobile Manufactors, "New energy vehicles enjoyed a high-speed growth," January 20, 2016. [Online]. Available: http://www.caam.org.cn/AutomotivesStatistic s/20160120/1305184260.html. [Accessed: February 25, 2016].

[31] statista, "Politisch gewünschte Anzahl der Elektroautos im Jahr 2020 nach Ländern," 2016. [Online]. Available: http://de.statista.com/statistik/daten/studie/180290/umfrage/politis ch-gewuenschte-anzahl-der-elektroautos-im-jahr-2020/. [Accessed: February 25, 2016].

[32] Statista, "Anzahl der Beschäftigten im Kfz-Gewerbe in Deutschland in den Jahren 2011 bis 2014 nach Berufsgrad," 2015. [Online]. Available: http://de.statista.com/statistik/daten/studie/ 39396/umfrage/anzahl-der-beschaeftigten-im-kfz-gewerbe/. [Accessed: August 4, 2015].

[33] Deutsche Automobil Treuhand GmbH, "DAT Report 2015," Ostfildern, Germany, 2015. 
[34] Kultusministerkonferenz, „Rahmenlehrplan für den Ausbildungsberuf Kraftfahrzeugmechatroniker und Kraftfahrzeugmechtaronikerin,“ KMK, 2013.

[35] Deutscher Feuerwehr Verband, "Feuerwehr-Statistik," [Online]. Available: http://www.feuerwehrverband.de/statistik.html. [Accessed: February 25, 2016].

[36] Economic Commission for Europe of the United Nations (UN/ECE), ECE R100: Uniform provisions concerning the approval of vehicles with regard to specific requirements for the elctric power train, Official Journal of the European Union, 2011.

[37] Society of Automotive Engineers, SAE J1766: Recommended Practice for Electric, Fuel Cell and Hybrid Electric Vehicle Crash Integrity Testing, 2014.

[38] B. Scrosati, J. Garche and W. Tillmetz, Advances in Battery Technologies for Electric Vehicle, Cambridge: Elsevier Science \& Technology, 2015.

[39] B. Crothers, "Tesla 'Most Popular' U.S. Electric Vehicle In Q1, While Norway Leads Globally, Says IHS," Forbes, July 13, 2015. [Online]. Available: http://www.forbes.com/sites/brookecrothers/2015/07/13/teslamost-popular-u-s-electric-vehicle-in-q1-while-norway-leadsglobally-says-ihs/. [Accessed: August 5, 2015].

[40] Nissan, "2015 LEAF - First Responder’s Guide," 2014.

[41] ZVEI - German Electrical and Electronic Manufacturers' Association, "Voltage Classes for Electric Mobility," Frankfurt am Main, Germany, 2013.

[42] Deutsche Gesetzliche Unfallversicherung, Training for work on vehicles with high voltage systems, Berlin, Germany: DGUV, 2012.

\section{AUTHORS}

Heiko Fechtner received his B.Sc. degree in electrical engineering from the Faculty of Information, Media and Electrical Engineering of the Cologne University of Applied Science, Germany, in 2010 and his M.Sc. degree in business administration and electrical engineering from the School of Electrical, Information and Media Engineering of the University of Wuppertal, Germany, in 2014. Since 2014 he is a researcher at the E-Mobility Research Group at the University of Wuppertal. His research interests are in the area of vehicle mass detection, range prediction of electric vehicles, and training programs for working on electric vehicles (e-mail: fechtner@uni-wuppertal.de).

Karl-Heinz Saes is a trainer for the qualification for working on electric vehicles at the Training Center KampLintfort of the TUV NORD Bildung GmbH \& Co. KG in Kamp-Lintfort, Germany (e-mail: ksaes@tuev-nord.de).

Erik Fechtner is a student assistant at the E-Mobility Research Group at the University of Wuppertal, Germany (e-mail: efechtner@uni-wuppertal.de).

Tobias Braun received his B.Sc. degree in economics in 2013 from the University of Bonn. Actually he is working on his master's thesis about service innovations and training requirements in the context of electric vehicles at the E-Mobility Research Group at the University of Wuppertal, Germany (e-mail: tobias.braun@uni-wuppertal.de).

Benedikt Schmuelling received the M.Sc. degree in electrical engineering from the Faculty of Electrical Engineering and Information Technology of Dortmund University, Germany, in 2005. From 2005 until 2010, he worked as a researcher at the Institute of Electrical Machines, RWTH Aachen University, Germany, where he also received his $\mathrm{PhD}$ in 2009. From 2010 until 2012 he was with Vahle Inc, Kamen, Germany, where he worked as an engineer on the development of wireless charging stations for electric vehicles. Since 2012 he is with the University of Wuppertal, Germany, where he is head of the E-Mobility Research Group at the School of Electrical, Information and Media Engineering. His research fields include electric mobility, wireless power transfer, automotive engineering, energy storage systems, and efficiency topics (e-mail: schmuelling@uni-wuppertal.de).

This article is an extended and modified version of a paper presented at the 2015 IEEE International Conference on Teaching, Assessment and Learning for Engineering (TALE2015), held 10-12 December, United International College (UIC) of the Beijing Normal University and Hong Kong Baptist University (HKBU), Zhuhai, China. Submitted 14 March 2016. Published as resubmitted by the authors 15 April 2016. 